\title{
Role of uterine artery doppler at 18-22 weeks in the prediction of pre-eclampsia: a prospective study
}

\author{
Patricia Malini Pereira*, Lakshmi Manjeera M., Valerie Anithra Pereira
}

Department of Obstetrics and Gynaecology, Justice K. S. Hegde Medical Academy, Mangalore, Karnataka, India

Received: 25 July 2020

Accepted: 04 September 2020

\section{*Correspondence:}

Dr. Patricia Malini Pereira,

E-mail: patriciapereira2511@gmail.com

Copyright: (c) the author(s), publisher and licensee Medip Academy. This is an open-access article distributed under the terms of the Creative Commons Attribution Non-Commercial License, which permits unrestricted non-commercial use, distribution, and reproduction in any medium, provided the original work is properly cited.

\begin{abstract}
Background: Pre-eclampsia is the most common pregnancy complication associated with serious maternal and fetal morbidity. Uterine artery Doppler reflects the impaired trophoblastic invasion of the uterine spiral arteries, which is involved in the aetiology of preeclampsia. Thus, uterine artery Doppler was proposed as a screening test for preeclampsia.

Methods: A prospective cohort study of 100 singleton pregnancies was conducted in a tertiary centre and the study population were subjected to uterine artery Doppler study at 18-22 weeks gestation. Uterine artery Doppler indices of pulsatility index (PI), resistance index (RI) and persistence of diastolic notch was obtained and the outcome of preeclampsia was studied.

Results: Out of 100 women, 14 women developed pre-eclampsia in which the resistance index showed a sensitivity of $21.4 \%$, specificity of $91.8 \%$, positive predictive value of $30 \%$ and negative predictive value of $87.7 \%$ and pulsatility index showed sensitivity of $35.7 \%$, specificity of $90.6 \%$, positive predictive value of $38.4 \%$ and negative predictive value of $89.6 \%$. Diastolic notch had a sensitivity of $35.7 \%$, specificity of $98.8 \%$, positive predictive value of $83.3 \%$ and a negative predictive value of $90.4 \%$.

Conclusions: The high negative predictive values, indicated that women with normal Doppler velocimetry were unlikely to develop preeclampsia. Uterine artery Doppler, being non-invasive can be included during routine sonography to identify patients at risk of developing pre-eclampsia. Early, screening for pre-eclampsia will help in individualized antenatal surveillance and initiation of prophylactic therapy, early to reduce the adverse maternal and foetal complications of preeclampsia.
\end{abstract}

Keywords: Diastolic notch, Pre-eclampsia, Pulsatility index, Resistance index

\section{INTRODUCTION}

Preeclampsia (PE) is a multisystem, pregnancy-specific disorder that is characterised by the development of hypertension (Blood pressure-140/90 mmHg) and proteinuria $(300 \mathrm{mg} / 24$ hours or $1+$ dipstick) after 20 weeks of gestation. ${ }^{1}$

The incidence of pre-eclampsia is higher in primigravida women, and in those who have a family or past history of hypertensive pregnancy. ${ }^{2}$
Preeclampsia is therefore characterized by an imbalance between prostacycline and thromboxane production, as well as failure of the second wave trophoblastic invasion of the endometrio-myometrial vasculature. The result is abnormal uteroplacental blood flow.

Since pre-eclampsia is described by uteroplacental insufficiency due to abnormal blood flow, the concept of utilising Doppler velocimetry as a part of routine ultrasonography to assess the blood flow was put forth. ${ }^{3,4}$ 
At 14-20 weeks gestation, there is a wave of trophoblast invasion into the maternal spiral arteries and the impedance decreases, which causes an increase in the blood flow. ${ }^{5,6}$

However in impaired trophoblastic invasion, this process does not occur and it results in a low velocity, high impedance circulation. During which, uterine artery Doppler studies show elevated Doppler indices values and persistent diastolic notching. The appearance of diastolic notching is rare until 26 weeks of gestation, however its presence is identified with an underlying pathological cause. An increased risk for pre-eclampsia more than 17 weeks is identified, when increased Doppler indices and the presence of end-diastolic notching is noted. This occurs as a result of increased resistance in the uteroplacental circulation. ${ }^{7-9}$ Hence the aim of this study is to evaluate the role of uterine artery Doppler at 18-22 weeks in the prediction of preeclampsia.

\section{METHODS}

In this prospective study, 100 participants were selected after taking informed consent and ethical clearance, from November 2016 till March 2018. Pregnant women attending antenatal clinic in the Department of Obstetrics and Gynaecology in Justice K. S. Hegde Charitable Hospital constituted the study population.

\section{Inclusion criteria}

All gravid women between 18-22 weeks of gestation having a 6-8 weeks scan.

\section{Exclusion criteria}

High risk patients like- chronic hypertension, diabetes mellitus, chronic renal disease, congenital anomalies and multiple pregnancy.

After informed consent and ethical clearance, all enrolled women were subjected to detailed history and clinical examination including recording of blood pressure manually, using a sphygmomanometer in position, height, weight, fundal height. Routine hematological investigations, serology and urine routine with urinary protein were done.

\section{Procedure}

The patient was put in supine position and then a detailed trans-abdominal ultrasonographic examination at 18 to 22 weeks to confirm the gestational age, presentation, liquor was done. Ultrasound machine (GE VOLUSON-730 EXPERT SERIES and PHILIPS HD 7XE) with a convex probe of 5-7 MHz with a high pass filter was used. Doppler mode was then switched on. With the transducer in the longitudinal plane, the external iliac artery was visualized at pelvic side wall with colour and spectral
Doppler. The transducer was then angled medially towards the uterine artery, where it crosses the external iliac artery. The flow velocity waveforms on the right and left uterine arteries were taken, when 3 or 4 waves of equal height were seen, the image was frozen and measurements were taken either by trace method/ manually/automatic trace. Then Doppler indices were obtained directly from the machine. Parameters of Mean PI, Mean RI and presence or absence of diastolic notch in bilateral uterine arteries were analysed.

The flow velocity waveforms were considered abnormal if there was diastolic notch in uterine artery in either right or left uterine arteries and if PI exceeded 1.45 and RI exceeded >0.7. ${ }^{10}$ Patients with normal and abnormal uterine artery Doppler values, were closely monitored and followed up till delivery. The collected information was summarized by using percentage for qualitative data. Sensitivity, Specificity, Positive predictive value, Negative predictive value were calculated using $2 \times 2$ table. The statistical analysis was done using SPSS (statistical package for social sciences) version 15.0 statistical analysis software.

\section{RESULTS}

Uterine artery Doppler were studied in all 100 cases and the outcome of pre-eclampsia was studied and statistical analysis was carried out using sensitivity specificity and predictive values. The results showed that among the study population of 100,14 patients developed preeclampsia, thus a prevalence of $14 \%$ was noted. Out of 14 patients who developed pre-eclampsia, majority were primigravid women, which constituted $57.2 \%$ of the preeclampsia population. Abnormal uterine artery Doppler was described by Doppler indices having a mean $\mathrm{PI}>1.45$, mean $\mathrm{RI}>0.7$ and persistence of diastolic notch. In our study of 100 gravid women, 13 patients had $\mathrm{PI}>1.45,10$ patients had $\mathrm{RI}>0.7$, and 6 patients had persistence of diastolic notch. In the pre-eclampsia patient group, it was noted that $64.3 \%$ had normal pulsatility index $(\mathrm{PI}<1.45)$ and $35.7 \%$ had pulsatility index $>1.45$ (Table 1).

Table 1: Relationship between pulsatility index and Pre-eclampsia.

\begin{tabular}{|c|c|c|c|c|c|}
\hline \multirow{2}{*}{$\begin{array}{l}\text { Pulsatility } \\
\text { index } \\
\text { (PI) }\end{array}$} & \multicolumn{2}{|c|}{ Pre-eclampsia } & \multirow[b]{2}{*}{ Total } & \multirow[b]{2}{*}{$\begin{array}{l}\text { Chi- } \\
\text { square }\end{array}$} & \multirow[b]{2}{*}{$\mathbf{P}$} \\
\hline & $\begin{array}{l}\text { Present } \\
\text { n }(\%)\end{array}$ & $\begin{array}{l}\text { Absent } \\
\text { n (\%) }\end{array}$ & & & \\
\hline$>1.45$ & $5(38 \%)$ & $8(62 \%)$ & 13 & \multirow{3}{*}{54.760} & \multirow{3}{*}{$0.00 *$} \\
\hline$<1.45$ & $\begin{array}{l}9 \\
(10.3 \%)\end{array}$ & $\begin{array}{l}78 \\
(89.7 \%)\end{array}$ & 87 & & \\
\hline Total & 14 & 86 & 100 & & \\
\hline
\end{tabular}

*Statistically significant, $\mathrm{p}<0.05$

Out of 13 patients who had PI>1.45, 38\% of the patients developed pre-eclampsia and $62 \%$ did not develop preeclampsia. Out of the remaining 87 patients who had $\mathrm{PI}<1.45,10.3 \%$ of the patients had developed pre- 
eclampsia and $89.7 \%$ of them did not develop preeclampsia.

\section{Table 2: Relationship between resistance index and Pre-eclampsia.}

\begin{tabular}{|c|c|c|c|c|c|}
\hline \multirow{2}{*}{$\begin{array}{l}\text { Resistance } \\
\text { index } \\
\text { (RI) }\end{array}$} & \multicolumn{2}{|c|}{ Pre-eclampsia } & \multirow{2}{*}{ Total } & \multirow{2}{*}{$\begin{array}{l}\text { Chi- } \\
\text { square }\end{array}$} & \multirow[b]{2}{*}{$\mathbf{P}$} \\
\hline & $\begin{array}{l}\text { Present } \\
\text { n }(\%)\end{array}$ & $\begin{array}{l}\text { Absent } \\
\text { n (\%) }\end{array}$ & & & \\
\hline$>0.7$ & $3(30 \%)$ & $7(70 \%)$ & 10 & \multirow{3}{*}{64.000} & \multirow{3}{*}{$0.00 *$} \\
\hline$<0.7$ & $\begin{array}{l}11 \\
(12.2 \%)\end{array}$ & $\begin{array}{l}79 \\
(89.8 \%)\end{array}$ & 90 & & \\
\hline Total & 14 & 86 & 100 & & \\
\hline
\end{tabular}

*Statistically significant, $\mathrm{p}<0.05$

In the pre-eclampsia patient group, majority $(78.6 \%)$ had normal resistance index $(\mathrm{RI}<0.7)$ while $21.4 \%$ had resistance index $>0.7$ (Table 2). Out of 10 patients, who had abnormal RI, 30\% developed pre-eclampsia. Out of 90 patients, who had $\mathrm{RI}<0.7,12.2 \%$ of the patients developed pre-eclampsia and $87.8 \%$ did not develop preeclampsia. It was found that $83.3 \%$ of the patients who had diastolic notching, had developed pre-eclampsia and 1 patient did not develop pre-eclampsia (16.7\%) (Table 3).
Table 3: Relationship between the presence of diastolic notch and pre-eclampsia.

\begin{tabular}{|lll|lll|}
\hline $\begin{array}{l}\text { Diastolic } \\
\text { notch }\end{array}$ & $\begin{array}{l}\text { Pre-eclampsia } \\
\text { Present } \\
\text { n(\%) }\end{array}$ & $\begin{array}{l}\text { Absent } \\
\text { n(\%) }\end{array}$ & Total & $\begin{array}{l}\text { Chi- } \\
\text { square }\end{array}$ & P \\
\cline { 1 - 4 } Present & $5(83.3 \%)$ & $1(16.7 \%)$ & 6 & & \\
\cline { 1 - 3 } & $9(9.6 \%)$ & $85(90.4 \%)$ & 94 & 77.440 & $0.00 *$ \\
\hline Total & 14 & 86 & 100 & & \\
\hline
\end{tabular}

*Statistically significant, $\mathrm{p}<0.05$

Out of the remaining 94 patients, who did not have diastolic notching, 9 patients had developed preeclampsia $(9.6 \%)$, and 85 patients did not develop preeclampsia $(90.4 \%)$. Thus, in this study resistance index showed a sensitivity of $21.4 \%$, specificity of $91.8 \%$, positive predictive value of $30 \%$ and negative predictive value of $87.7 \%$. Pulsatility index showed a sensitivity of $35.7 \%$, specificity of $90.6 \%$, positive predictive value of $38.4 \%$ and negative predictive value of $89.6 \%$. Diastolic notch had a sensitivity of $35.7 \%$, specificity of $98.8 \%$, positive predictive value of $83.3 \%$ and a negative predictive value of $90.4 \%$ (Table 4).

Table 4: Sensitivity, specificity, positive predictive value and negative predictive values for the Doppler indices.

\begin{tabular}{|lllll|}
\hline Doppler indices & Sensitivity & Specificity & Positive predictive value & Negative predictive value \\
\hline Pulsatility index & $35.7 \%$ & $90.6 \%$ & $38.4 \%$ & $89.6 \%$ \\
\hline Resistance index & $21.4 \%$ & $91.8 \%$ & $30.0 \%$ & $87.7 \%$ \\
\hline Diastolic notch & $35.7 \%$ & $98.8 \%$ & $83.3 \%$ & $90.4 \%$ \\
\hline
\end{tabular}

\section{DISCUSSION}

In the past decades, the prediction of pre-eclampsia has been attempted by using several methods. In this respect, Doppler flow studies of the uteroplacental circulation have been extensively performed, since they are easy, inexpensive, non-invasive and can be done in early pregnancy. However, Doppler ultrasound examination of the uteroplacental circulation has provided conflicting results when employed as a screening test for preeclampsia of pregnancy. The timing of examining the uterine Doppler flow has been studied extensively. The persistence of diastolic notch in the flow velocity waveforms and Doppler indices having a higher value after the $20^{\text {th }}$ week gestation, characterises high resistance to the flow and is considered abnormal. ${ }^{11}$

In the present study, out of 100 patients studied, 14 (14\%), developed preeclampsia. In the preeclampsia patient group RI was greater than 0.7 in 3 patients $(21.5 \%)$, whereas $11(78.5 \%)$ patients had normal RI. Whereas PI was $>1.45$ in 5 women $(35.7 \%)$ only. These results were compared to the results obtained by Brig Sahoo et al wherein 54 out of the 220 patients studied developed pre-eclampsia, and in the pre-eclampsia patient group, RI was greater than 0.7 ( $>0.7$ at 95 percentile) in 42 patients, whereas 12 patients had normal RI. ${ }^{12}$ PI was $>1.4$ in 24 women only. Thus, RI had a sensitivity, specificity, positive predictive value, negative predictive value of $77.8 \%, 85.5 \%, 63.6 \%, 92.2 \%$ respectively and PI had a sensitivity, specificity, positive predictive value, negative predictive value of $44.44 \%, 89.75 \%, 58.53 \%$, $83.24 \%$ respectively. In our study, resistance index showed sensitivity of $21.4 \%$, specificity of $91.8 \%$, positive predictive value of $30 \%$ and negative predictive value of $87.7 \%$ and pulsatility index showed sensitivity of $35.7 \%$, specificity of $90.6 \%$, positive predictive value of $38.4 \%$ and negative predictive value of $89.6 \%$.

Padmalatha et al studied 217 women with singleton pregnancy between 20-24 weeks who were subjected to uterine artery Doppler studies, and PI and RI, both had sensitivity of $60 \%$, specificity of $92 \%$, positive predictive value of $16 \%$, negative predictive value $99 \% .^{13}$

Bower et al examined the uterine arteries in 2058 pregnancies at $18-22$ weeks the value of the early diastolic notch and colour Doppler imaging of the uterine arteries at 24 weeks' gestation in a two-stage Doppler screening test for pre-eclampsia. ${ }^{14}$ Abnormal results were 
defined as an RI > ninety-fifth percentile or the presence of early diastolic notches in either of the uterine arteries, which was found in $16 \%$ of the pregnancies. They found a sensitivity of $75 \%$ for pre-eclampsia.

Barati et al studied three hundred and seventy-nine women were subjected to a uterine artery Doppler study, between 16-22 weeks of gestation, and PI showed a higher sensitivity of $79 \%$, specificity of $95.5 \%$, positive predictive value- $88.4 \%$ and negative predictive value of $98.9 \%$, probably because of a larger population group studied. ${ }^{15}$

Pranita et al studied 140 women, out of which 28 women had abnormal uterine artery Doppler values and only 8 developed pre-eclampsia. ${ }^{16}$ RI as a predictor of preeclampsia (RI>0.58), showed a sensitivity of $50 \%$, specificity of $93.9 \%$, positive predictive value of $33.3 \%$ and negative predictive value of $96.9 \%$. Notching had a sensitivity of $62.5 \%$, specificity of $94.7 \%$, and positive predictive value of $41.7 \%$ and negative predictive value of $97.7 \%$.

Yang et al studied 2039 singleton pregnancies and uterine artery Doppler was done at 21 weeks of gestation and PI showed sensitivity of $83.8 \%$, specificity of $91.9 \%$, positive predictive value- $49.1 \%$ and negative predictive value of $79.5 \%$ for predicting the risk of HDP. ${ }^{17}$

The limitation of this study was that, it was conducted at a medical college and hospital which was a tertiary health centre so demographic data may not represent the sample of population of the region. The short time period of the study and the small number of cases studied are further shortcomings of this study.

\section{CONCLUSION}

Second trimester uterine artery- pulsatility index, resistance index and the presence of diastolic notch can be used as a predictor for pre-eclampsia. The uterine artery Doppler data of this study suggest that preeclampsia is strongly associated with defective invasion of the spiral arteries. Presence of diastolic notch in the uterine artery is better than the individual Doppler indices of pulsatility index and resistance index to rule out preeclampsia. By obtaining high negative predictive values, we can conclude that women with normal Doppler velocimetry are unlikely to develop pre-eclampsia. Although the uterine artery Doppler has a high negative predictive value for the prediction of pre-eclampsia, the strength of the association between abnormal results is not so considerable to justify its introduction as a screening test. Uterine artery Doppler, being non-invasive can be included during routine sonography to identify patients at risk of developing pre-eclampsia. Early screening for pre-eclampsia will help in vigilant and individualized antenatal surveillance and initiation of prophylactic therapy, early to reduce the adverse maternal and foetal complications of pre-eclampsia.

\section{Recommendations}

It is recommended that further studies be done on a larger scale to represent the general population. Further studies, combining Doppler velocimetry along with biochemical tests, will prove more effective in screening patients for pre-eclampsia.

\section{ACKNOWLEDGMENTS}

The authors would like to thank the women for participating in this study and the residents in the department of Obstetrics and Gynaecology for their support.

Funding: No funding sources

Conflict of interest: None declared

Ethical approval: The study was approved by the Institutional Ethics Committee

\section{REFERENCES}

1. Wagner LK. Diagnosis and management of preeclampsia. Am Fam Phys. 2004;70(12):2317-24.

2. Hjartardoltir S, Leifsson BG, Geirsson RT, Steinthrosdottir V. Paternity change and the recurrence risk in familial hypertensive disorder in pregnancy. Hypertens Pregnancy. 2004;23(2):21925.

3. Khong TY, De Wolf F, Robertson WB, Brosens I. Inadequate maternal vascular response to placentation in pregnancies complicated by preeclampsia and by small-for-gestational age infants. Br J Obstet Gynaecol. 1986;93:1049-59.

4. Steel SA, Pearce JM, Chamberlain G. Doppler ultrasound of the uteroplacental circulation as a screening test for severe pre-eclampsia with intrauterine growth retardation. Eur J Obstet Gynecol Reprod Biol. 1988;28:279-87.

5. Huppertz B. Placental origins of preeclampsia: challenging the current hypothesis. Hypertension. 2008;51(4):970-5.

6. Ghosh SK, Raheja S, Tuli A, Raghunandan C, Agarwal S. Combination of uterine artery Doppler velocimetry and maternal serum placental growth factor estimation in predicting occurrence of preeclampsia in early second trimester pregnancy: a prospective cohort study. Eur J Obstet Gynecol Reprod Biol. 2012;161(2):144-51.

7. Abramowicz JS, Sheiner E. Ultrasound of the placenta: a systematic approach. Part II: functional assessment (Doppler). Placenta. 2008;29(11):921-9.

8. Kalache KD, Dückelmann AM. Doppler in obstetrics: beyond the umbilical artery. Clin Obstet Gynecol. 2012;55(1):288-95.

9. Papageorghiou AT, Leslie K. Uterine artery Doppler in the prediction of adverse pregnancy outcome. Curr Opin Obstet Gynecol. 2007;19(2):103-9.

10. Adekanmi AJ, Roberts A, Adeyinka AO, Umeh EO, Anor F, Odo JC, et al. Normal second and third 
trimester uterine and umbilical Doppler indices among healthy singleton gestation Nigerian women. West Afr J Radiol. 2017;24:1-7.

11. Fleisher A, Schulman H, Farmakides G, Bracero L, Rochelson B, Grunfeld L, et al. Uterine artery Doppler velocimetry in pregnant women with hypertension. Am J Obstet Gynecol. 1986;154:806-13.

12. Sahoo BK, Shaha P, Bhairagond S, Raj VR. The role of uterine artery doppler sonography in predicting pre eclampsia at 14-20 weeks of gestation. Int J Sci Res. 2016;5(2):37-47.

13. Padmalatha VV, Rao PSS, Abraham S, Thomas A. Predicting pre-eclampsia and foetal growth restriction through second trimester uterine artery Doppler sonography: an Indian experience. IOSR J Dent Med Sci. 2013;12(1):21-6.

14. Bower S, Susan B, Campbell S. Improved prediction of pre-eclampsia by two stage screening of uterine arteries using the early diastole notch and colour Doppler imaging. Obstet Gynecol. 1993;82;78-83.
15. Barati M, Shahbazian N, Ahmadi L, Masihi S. Diagnostic evaluation of uterine artery Doppler sonography for the prediction of adverse pregnancy outcomes. J Res Med Sci. 2014;19:515-9.

16. Rupnawar PB, Ajith S. To assess uterine artery doppler findings at 18-22 weeks in predicting adverse pregnancy outcome. IOSR J Dent Med Sci. 2015;14(8):95-100.

17. Yang SW, Cho SH, Kang YS, Park SH, Sohn IS, Kwon HS, et al. Usefulness of uterine artery Doppler velocimetry as a predictor for hypertensive disorders in pregnancy in women with prehypertension before 20 weeks gestation. PLoS One. 2019;14(1):1-9.

Cite this article as: Pereira PM, Lakshmi MM,

Pereira VA. Role of uterine artery doppler at 18-22 weeks in the prediction of pre-eclampsia: a prospective study. Int J Reprod Contracept Obstet Gynecol 2020;9:4130-4. 